\title{
Stochastic Analysis of Maize (Zea mays) Production in Betul and Madhya Pradesh, India
}

\author{
R.B. Singh ${ }^{1}$, Navneet Rathore ${ }^{1}$, S.K. Pysai ${ }^{2}$, Umesh Singh $^{3}$ and P. Mishra ${ }^{4}$ \\ ${ }^{1}$ Department of Mathematics \& Statistics, JNKVV, Jabalpur, 482004 (M.P.), India \\ ${ }^{2}$ College of Agriculture Engineering, JNKVV Jabalpur, India \\ ${ }^{3}$ College of agriculture, Tikamgarh, (M.P.), JNKVV, India \\ ${ }^{4}$ College of agriculture, Powarkheda, (M.P.), JNKVV, 461110, India
}

*Corresponding author

\begin{tabular}{|c|c|}
\hline & A B S T R A C T \\
\hline Keywords & \multirow{4}{*}{$\begin{array}{l}\text { The purpose of present study was to describe the growth rate study for some time series } \\
\text { production factors of maize and also making of diagnostic study for detecting some } \\
\text { influential time series production factors governing total Maize production in Betul district } \\
\text { and also in Madhya Pradesh during the period } 1988-2017 \text {. The secondary data was } \\
\text { collected for analysis from Directorate of economics and statistics and } \\
\text { http://mpkrishi.mp.gov.in. The maximum compound growth rate had been obtained at } \\
\text { fertilizer distribution of maize i.e. } 10.8 \text { percent in Betul but the minimum support price of } \\
\text { maize i.e. } 8.20 \text { percent in Madhya Pradesh. The minimum growth rate is observed in area } \\
\text { of maize i.e. } 1 \text { percent in Madhya Pradesh but the productivity of Maize i.e. } 2.60 \text { percent in } \\
\text { Betul. Correlation and path analysis delineated that the area and the price of maize had a } \\
\text { high positive effect of } 2.812 \text { and } 1.014 \text { in Betul District. }\end{array}$} \\
\hline $\begin{array}{l}\text { Maize, Correlation } \\
\text { coefficient, Compound } \\
\text { growth rate }\end{array}$ & \\
\hline Article Info & \\
\hline $\begin{array}{l}\text { Accepted: } \\
\text { 18 September } 2018 \\
\text { Available Online: } \\
10 \text { October } 2018\end{array}$ & \\
\hline
\end{tabular}

\section{Introduction}

Maize (Zea mays) is the third most important cereal crop in the world after wheat and rice. Maize is a domesticated grass of tropical mexican origin which belongs to large and important family of Poaceae. It is a tropical crop and most of the area under this crop is however in the warmer parts of temperate region and in humid subtropical climate and is highest in area having the warmest month isotherms from $21^{\circ} \mathrm{c}$ to $27^{\circ} \mathrm{c}$ and a frostfree season of (120 180) days. Maize grains serve as raw material for manufacture of starch, syrup, dextrose, maltoidextrin, oil, lactic acid and butyl alcohol. In truth starch serve as raw material for paper, textile, adhesive, binding material, braveries and pharmaceutical industries. In India during 2011-12 maize was cultivated in area of about 7.27 million hectare with a production of about 15.86 million tonnes and $2181 \mathrm{~kg} / \mathrm{ha}$ productivity (Agropedia, 2011-12). Madhya Pradesh is a maize producing state contributing (5.7 percent) to the national production.

During 2015-16 maize was cultivated in an area about 1098ha. With production of 2580.3 tones and $2350 \mathrm{~kg} /$ hectare productivity. (http://mpkrishi.mp.gov.in.) 
In Betul, during 2015-16 maize was cultivated in an area of about 56.50 ha with the production of 133 tones and $2355 \mathrm{~kg} / \mathrm{ha}$ productivity (http:/www.mp.gov.in/en/mpkrishi/arg-st/districtwisearea).

\section{Materials and Methods}

The data were collected from Directorate of Economics and Statistics and http://mpkrishi.mp.gov.in.

In accordance with the objectives delineated, the time-series data pertaining to five important factors viz. $\mathrm{X}_{1}=$ Area ('000' ha.), $\mathrm{X}_{2}=$ Production ('000' $\mathrm{t}$ ) $\mathrm{X}_{3}=$ Productivity $(\mathrm{t} / \mathrm{ha}), \mathrm{X}_{4}=$ Minimum statutory price $(\mathrm{Rs} / \mathrm{Q})$, $\mathrm{X}_{5}=$ Fertilizer distribution ('000't) of 30 years (1988 to 2017) both for Betul district and Madhya Pradesh state as a whole.

\section{Growth rate study of time series production factors on maize}

In order to study the growth rate, the wellknown growth model was fitted with respect to each factor. The model is

$X_{i t}=\alpha \beta^{t} \xi_{i t} ; \quad i=1,2,3 \ldots .5 ; t=1,2,3 \ldots \ldots .30$,

Where, $X_{i t}$ is the response of the $i^{\text {th }}$ factor in the $t^{\text {th }}$ year, $\alpha \beta$ are unknown parameters to be estimated in the model, $\mathrm{t}$ is time element which takes the value $1,2,3, \ldots . \mathrm{n}$ and $\xi_{\mathrm{it}}$ is multiplicative error [ $\xi_{\mathrm{it}}$ 's $\square \operatorname{IID}\left(0, \sigma^{2}\right]$

The above growth model was linearised by using logarithmic transformation and the unknown parameter was estimated by ordinary least square (OLS) method.

From the fitted model compound growth rate percent was computed as:

$\mathrm{CGR}=(\text { Antilog } \mathrm{b}-1)^{*} 100$, where, $\mathrm{b}$ is estimated value of $\beta$.
Singh et al., (2012) pointed out that the major factors influencing the productivity for maize in Betuldistrict.

Statistical Diagnostics 340 testing the influential times reproduction factors governing total Maize production

Simple correlation coefficients among the five factors were computer to study the strengths of their interrelationships in respect of Betul district and Madhya Pradesh as a whole. Correlation does not say anything about the cause and effect relationship. Sewall Wright (1921) developed and applied the method of path analysis for the purpose of interpretation of a system of correlation coefficient in terms of path of causation. To diagnose the important factors which have their direct and indirect influence on the total maize production, the technique of path coefficient analysis has been employed. If $\mathrm{Y}$ is the effect and $X_{1}, X_{2}$ and $X_{3}$ are causal factors, then the set of equations are

$$
\begin{aligned}
& r_{1 y}=P_{1 Y}+r_{12} P_{2 Y}+r_{13} P_{3 Y} \\
& r_{2 y}=r_{21} P_{1 Y}+P_{2 Y}+r_{23} P_{3 Y} \\
& r_{3 y}=r_{31} P_{1 Y}+r_{32} P_{2 Y}+P_{3 Y}
\end{aligned}
$$$$
\text { (Sahu and das, 2009) }
$$

Where, $r_{1 y}, r_{2 y}$ and $r_{3 y}$ are the simple correlation coefficient between each of the causal factors with the effect, $\mathrm{Y}$ and $\mathrm{P}_{1 \mathrm{y}}, \mathrm{P}_{2 \mathrm{y}}$, and $\mathrm{P}_{3 \mathrm{y}}$ are direct effects of the causal factors to the effect $Y$. The residual effect (effect due to the casual factors to the effect, $\mathrm{Y}$ which have not been included in the analysis) $h$, is computed as-

$$
\square=\sqrt{1-r_{1 Y} P_{1 Y-} r_{2 Y} P_{2 Y}-r_{3 Y} P_{3 Y}}
$$

\section{Results and Discussion}

The results emanated from the data considered under the purview of this investigation are 
presented as follows: Table 1 reveals the growth dynamics of maize production factors for Madhya Pradesh and Betul. It is seen that the maximum compound growth rate had been obtained at the fertilizer distribution of maize i.e. 10.8 percent in Betul but the minimum support price of maize i.e. 8.20 percent in Madhya Pradesh. The minimum growth rate is observed in the area of maize i.e. 1 percent in Madhya Pradesh but the productivity of maize i.e. 2.60 percent in Betul. The maize productivity in Madhya Pradesh as well as Betul had been found the minimum growth rate; it mean that the farmers may divert their lands for another crop so there is need to increase the yield by the use of high yielding varieties and other crop management practices.

Table 2 shows that the average area of maize in Madhya Pradesh is 847.72, where as in Betul district 31.26 and percentage contribution of Betul to Madhya Pradesh 3.68 percent with coefficient of variation 12.34 percent and 57.29 percent respectively. The average production of maize in Madhya Pradesh 1284.25 percent and percentage contribution of Betul to Madhya Pradesh is 4.28 percent with coefficient of the variation 38.66 percent and 80.85 percent respectively and the average productivity of maize in Madhya Pradesh is $1480 \mathrm{~kg} / \mathrm{ha}$ and percentage contribution of Betul to Madhya Pradesh age 106.76 percent with coefficient of variation 26.24 percent and 14.61 percent respectively. The average minimum support price in Madhya Pradesh is 585. 17 and coefficient of variation 66.99 as well as Betul and percentage contribution of Betul to Madhya Pradesh is 100 percent. The average fertilizer distribution in Madhya Pradesh is 342.04 where in Betul district 14.27 and percentage contribution of Betul to Madhya Pradesh is 4.17 percent with coefficient of variation 45.88 percent and 81.96 percent respectively.
A simple technique for calculation of path coefficient taking correlation matrix among X's variable had been used. The correlation coefficient for the different pairs of variables are assessed and shown in Table 3. Path analysis results aimed to diagnose the direct and indirect effect of important factors on the total maize production which is summarised in Table 4 with respect to Betul and Madhya Pradesh as a whole respectively. From the Table 3, it is observed that the production of maize is positively correlated with maize area (0.837), productivity (0.781), minimum support price (0.769) and fertilizer distribution (0.859). It was also noticed that the area, productivity, minimum support price and fertilizers distribution has a significant relationship with the maize production. These components exhibited interrelationship with each other. This shows that the importance of these components as production attributing factors. It has been observed that the production of maize is positively correlated with maize area (0.900), productivity (0.957), minimum support price (0.734) and fertilizers distribution (0.800). From the table it was also noticed that area, productivity, minimum support price and fertilizer distribution has the significant relationship with the maize production. These components exhibit interrelationship with each other. This shows the importance of these components as production attributing factors.

The analysis in Table 4 shows that the diagonal elements represent direct effects and the off -diagonal elements represent indirect effects. This indicates that area had a high positive effect of (2.812) followed by price of maize (1.014) on total maize production in Betel district. Table 4 represents the path coefficient analysis between selected parameters and maize production in Madhya Pradesh. The analysis shows that the diagonal elements are direct effect and the off-diagonal elements represent indirect effect. 
Table.1 Fitted the growth models and compound growth rates of factors of Maize during 1988 to 2017

\begin{tabular}{|l|l|l|l|c|}
\hline \multirow{2}{*}{ Factors } & \multicolumn{2}{|c|}{ Fitted growth models } & \multicolumn{2}{c|}{ CGR $(\%)$} \\
\cline { 2 - 6 } & \multicolumn{1}{|c|}{ MP } & \multicolumn{1}{c|}{ Betul } & MP & Betul \\
\hline $\mathrm{X}_{1}$ & $\mathrm{X}_{1}=719.84 \times 1.010^{\mathrm{t}}$ & $\mathrm{X}_{1}=10.18 \times 1.063^{\mathrm{t}}$ & 1.00 & 6.30 \\
\hline $\mathrm{X}_{2}$ & $\mathrm{X}_{2}=799.03 \times 1.027^{\mathrm{t}}$ & $\mathrm{X}_{2}=10.61 \times 1.089^{\mathrm{t}}$ & 2.70 & 8.90 \\
\hline $\mathrm{X}_{3}$ & $\mathrm{X}_{3}=1.09 \times 1.017^{\mathrm{t}}$ & $\mathrm{X}_{3}=0.99 \times 1.026^{\mathrm{t}}$ & 1.70 & 2.60 \\
\hline $\mathrm{X}_{4}$ & $\mathrm{X}_{4}=138.95 \times 1.053^{\mathrm{t}}$ & $\mathrm{X}_{4}=138.28 \times 1.082^{\mathrm{t}}$ & 8.20 & 8.20 \\
\hline $\mathrm{X}_{5}$ & $\mathrm{X}_{5}=138.95 \times 1.053^{\mathrm{t}}$ & $\mathrm{X}_{5}=1.96 \times 1.108^{\mathrm{t}}$ & 5.30 & 10.8 \\
\hline
\end{tabular}

Table.2 Averages, coefficient of variation with respect to maize factors and their percentage contributions to Madhya Pradesh from Betul district during 1988 to 2017

\begin{tabular}{|c|c|c|c|c|c|}
\hline \multirow{2}{*}{ Factors } & \multicolumn{2}{|c|}{ MIP } & \multicolumn{2}{c|}{ Betul } & Percentage of Betul to M.P \\
\cline { 2 - 6 } & Mean & C.V.(\%) & Mean & C.V.(\%) & \\
\hline $\mathbf{X}_{1}$ & 847.72 & 12.34 & 31.26 & 57.29 & 3.68 \\
\hline $\mathbf{X}_{2}$ & 1284.25 & 38.66 & 54.93 & 80.85 & 4.28 \\
\hline $\mathbf{X}_{3}$ & 1480.0 & 26.24 & 1580.00 & 40.61 & 106.76 \\
\hline $\mathbf{X}_{4}$ & 585.17 & 66.99 & 585.17 & 66.99 & 100 \\
\hline $\mathbf{X}_{5}$ & 342.04 & 45.88 & 14.27 & 81.96 & 4.17 \\
\hline
\end{tabular}

Table.3 Correlation of maize production in Betul and Madhya Pradesh

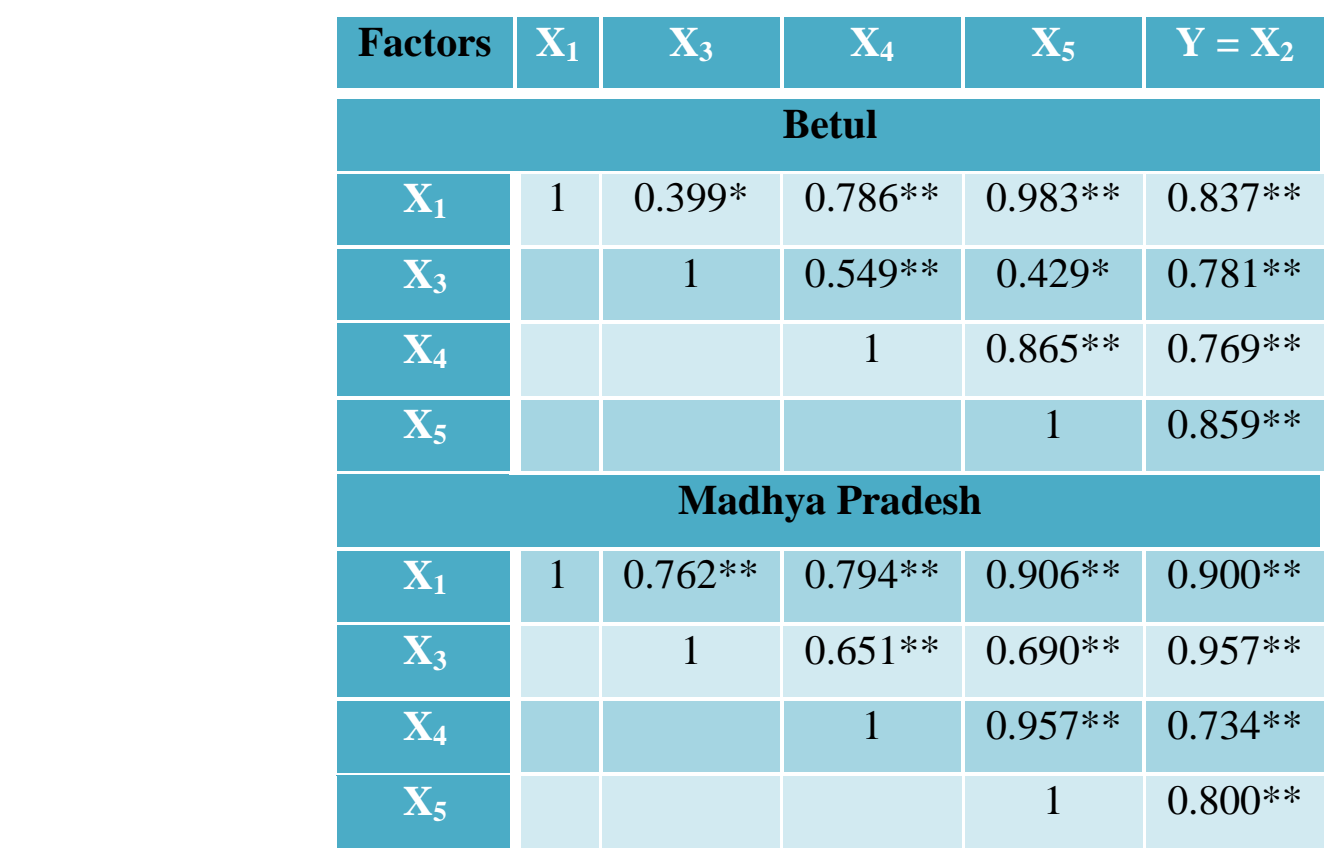

** Correlation is significant at $1 \%$ level, *correlation is significant at $5 \%$ level 
Table.4 Path coefficient analysis of maize production in Betul and Madhya Pradesh

\begin{tabular}{|c|c|c|c|c|}
\hline \multirow{2}{*}{ Parameters } & $\mathbf{X}_{\mathbf{1}}$ & \multicolumn{1}{|c|}{$\mathbf{X}_{\mathbf{3}}$} & $\mathbf{X}_{4}$ & $\mathbf{X}_{\mathbf{5}}$ \\
\hline & \multicolumn{3}{|c|}{ Betul } \\
\hline $\mathbf{X}_{\mathbf{1}}$ & $\mathbf{2 . 8 2 1}$ & 0.150 & 0.796 & -2.921 \\
\hline $\mathbf{X}_{\mathbf{3}}$ & 1.124 & $\mathbf{0 . 3 7 5}$ & 0.556 & -1.275 \\
\hline $\mathbf{X}_{4}$ & 2.209 & 0.206 & $\mathbf{1 . 0 1 4}$ & $-2,660$ \\
\hline $\mathbf{X}_{5}$ & 2.763 & 0.161 & 0.907 & $\mathbf{- 2 . 9 7 2}$ \\
\hline \multicolumn{4}{|c|}{ Madhya Pradesh } \\
\hline $\mathbf{X}_{\mathbf{1}}$ & $\mathbf{0 . 5 7 2}$ & 0.477 & 0.145 & -0.295 \\
\hline $\mathbf{X}_{3}$ & 0.437 & $\mathbf{0 . 6 2 6}$ & 0.120 & -0.224 \\
\hline $\mathbf{X}_{4}$ & 0.145 & 0.407 & $\mathbf{0 . 1 8 3}$ & -0.311 \\
\hline $\mathbf{X}_{5}$ & 0.519 & 0.432 & 0.175 & $\mathbf{0 . 3 1 1}$ \\
\hline
\end{tabular}

Table.5 Direct and indirect influence of maize factors on the total maize production in Betul and Madhya Pradesh

\begin{tabular}{|c|c|c|c|c|}
\hline Factors & $\begin{array}{c}\text { Direct } \\
\text { influences }\end{array}$ & $\begin{array}{l}\text { Rank of direct } \\
\text { influences }\end{array}$ & $\begin{array}{l}\text { Total indirect } \\
\text { influence }\end{array}$ & $\begin{array}{c}\text { Rank of indirect } \\
\text { influence }\end{array}$ \\
\hline \multicolumn{5}{|c|}{ Betul } \\
\hline $\mathbf{X}_{1}$ & 2.812 & 1 & -1.975 & 3 \\
\hline $\mathbf{X}_{\mathbf{3}}$ & 0.375 & 3 & 0.405 & 2 \\
\hline $\mathbf{X}_{4}$ & 1.014 & 2 & -0.245 & 4 \\
\hline $\mathrm{X}_{\mathbf{5}}$ & -2.972 & 4 & 3.831 & 1 \\
\hline \multicolumn{5}{|c|}{ Madhya Pradesh } \\
\hline$\overline{X_{1}}$ & 0.572 & 2 & 0.327 & 3 \\
\hline $\mathbf{X}_{3}$ & 0.626 & 1 & 0.333 & 2 \\
\hline $\mathrm{X}_{4}$ & 0.183 & 3 & 0.241 & 4 \\
\hline $\mathbf{X}_{\mathbf{5}}$ & -0.325 & 4 & 1.126 & 1 \\
\hline
\end{tabular}

This table indicates that the productivity had highest direct positive effect (0.626) followed by area $(0.572)$ on total maize production in Madhya Pradesh. The study reveals the direct and indirect contribution of maize production factors in Betul district and Madhya Pradesh is given in Table 5. Table 5 portrays corresponding scenario prevailing with respect of Betul. In fact, it reveals that maize area is most direct influential factor for Maize production with rank $1^{\text {st }}$ followed by price of maize with rank $2^{\text {nd }}$ followed by productivity, fertilizer distribution. The indirect effects corresponding to order (again based on magnitude of indirect effects) have the maximum magnitude of fertilizer distribution with rank $1^{\text {st }}$ followed by maize productivity, which attained the rank $2^{\text {nd }}$ followed by maize area rank $3^{\text {rd }}$. The findings emanated from the above result of delineated below with respect to Madhya Pradesh and are presented in Table 5. The value of positive direct effects of the all factors in the total maize production in Madhya Pradesh. The total maize production has a direct effect on the maize productivity rank 1 followed by maize area rank 2 , price of maize rank 3 then fertilizer distribution in Madhya Pradesh. It was found that the 
corresponding descending order with respect to the factors was fertilizer distribution via area of maize then the price of maize respectively.

Based on the above finding it may be concluded that an increased in factors like area will enhance maize production in Betul and Madhya Pradesh respectively by directly and indirectly. Specifically, the factors viz., maize area, production, productivity affected by minimum support price and fertilizers distribution. This study brings out the fact that the relationship between time series production factors and help to maize production.

\section{Acknowledgement}

The authors are grateful to the dean and head, department of mathematics and Statistics
JNKVV, Jabalpur, Madhya Pradesh for valuable suggestions and facilities.

\section{References}

Directorate of economics and statistics

Mpkrishi.org. http://mpkrishi.mp.gov.in/hindisite/inde xhindi.aspx

Sahu, P.K. and Das, A.K. (2009). Agricultural and applied statistics-II Kalyani publishers, New Delhi. 388 p.

Sewall Wright (1921). Correlation and Causation. 29 p.

Singh, N.R., Ambika R., Meena, S., Jat, S.L., Kumar, R. and Kumar, S. (2012). "Rabi maize opportunity challenges". Directorate of maize research Pusa Campus, New Delhi-110012, Technical Bulletin, 9:32p

\section{How to cite this article:}

Singh, R.B., Navneet Rathore, S.K. Pysai, Umesh Singh and Mishra, P. 2018. Stochastic Analysis of Maize (Zea mays) Production in Betul and Madhya Pradesh, India. Int.J.Curr.Microbiol.App.Sci. 7(10): 2446-2451. doi: https://doi.org/10.20546/ijcmas.2018.710.283 